\title{
Demandas ambientais na Educação Física Escolar: perspectivas de adaptação e de transformação
}

\author{
Luiz Sanches Neto* \\ Willian Lazaretti da Conceição*** \\ Tiemi Okimura-Kerr ${ }^{* * *}$ \\ Luciana Venâncio**** \\ Audrei Juliana Zeferino Vogel ${ }^{* * * * *}$ \\ André Luiz França ${ }^{* * * * * *}$ \\ Luciano Nascimento Corsino ${ }^{* * * * * * * * * *}$ \\ Jéssica Camila Ramos Rodrigues ${ }^{* * * * * * * * *}$ \\ Tatiana Pereira de Freitas ${ }^{* * * * * * * * *}$
}

\begin{abstract}
Resumo: Neste trabalho, tratamos da possibilidade do ensino de temas que remetem às demandas do ambiente na prática pedagógica da Educação Física. Identificamos e classificamos essas demandas como administrativas e econômicas, estéticas e filosóficas, virtuais, históricas e geográficas, sociológicas e políticas, físicas e naturais. Discutimos como as dinâmicas específicas - da cultura, do movimento, do corpo e do ambiente - permitem suscitar certos questionamentos sobre a pertinência da temática e suas repercussões na profissionalidade dos docentes. Consideramos que, no contexto da intervenção cotidiana, há perspectivas de adaptação e de transformação que podem ser aprofundadas em conjunto com os alunos durante as aulas.
\end{abstract}

Palavras-chave: Currículo. Educação Física. Fatores socioeconômicos. Características Culturais.

\footnotetext{
*Pós-graduação em Educação Física. Universidade Estadual Paulista, Rio Claro, SP, Brasil. Email: luizitosanches@yahoo.com

${ }^{*}$ Doutorando em Educação - Unicamp. Professor na Universidade do Estado da Bahia Departamento de Educação - Campus XII E-mail: will_lazaretti@hotmail.com

***Professora. Centro Universitário Sant'Anna. Rede Estadual de Educação de São Paulo, Brasil. E-mail: tiemiok@yahoo.com

****Pós-graduação em Educação. Universidade Estadual Paulista, Presidente Prudente, SP, Brasil. E-mail: luciana_venancio@yahoo.com.br

*****Centro de Educação Física e Desportos. Universidade Federal do Espírito Santo, Vitória, ES, Brasil. E-mail: auvogel@gmail.com.br

*****Professor. Rede Municipal de Educação de São Paulo, SP, Brasil. E-mail: andrelusax@yahoo.com.br

******Professor. Rede Municipal de Educação de São Paulo, SP, Brasil. E-mail: luciano.corsino@hotmail.com

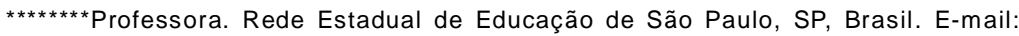
jessicacam@hotmail.com

********* Professora. Centro Universitário Nove de Julho e da Rede Estadual de Educação de São Paulo, SP, Brasil. E-mail: tatipfreitas@gmail.com
} 


\section{INTRODUÇÃO}

A preocupação com o ambiente na escolarização é comumente associada com preocupações ecológicas. Na Educação Física (EF), geralmente essa retórica enfatiza o uso de materiais adaptados ou recicláveis como estratégia sustentável. Este trabalho, porém, aborda outro ponto de partida: buscamos investigar possibilidades para ensinar temas referentes às demandas do ambiente em uma perspectiva ampliada. O ambiente remete a tudo aquilo que há no mundo e, nesse sentido, as demandas ambientais nos envolvem constantemente, influenciando e sendo influenciadas pelos acontecimentos cotidianos.

Porém, como afirma Larrosa Bondía (2002), nem tudo o que acontece ao nosso redor "nos acontece" como sujeitos de experiência. Assim, embora sejam várias as demandas do ambiente, apenas as que dizem respeito diretamente à experiência dos sujeitos nas situações interativas de ensino e de aprendizado decorrentes das aulas são significativas.

Pautamo-nos na sistematização de conteúdos e temas apresentada por Sanches Neto e Betti (2008), que apontaram a possibilidade de se integrar na prática pedagógica quatro blocos temáticos que seriam convergentes: elementos culturais, movimentos, aspectos pessoais e demandas ambientais. As dinâmicas que denotam a especificidade da EF seriam tratadas em temas referentes à cultura, ao movimento, ao corpo e ao ambiente.

Em recente trabalho de revisão do "estado da arte" das pesquisas brasileiras acerca da sistematização de conteúdos, Matos et al. (2013) apontaram 146 publicações sobre os elementos da cultura - como Dança, Ginástica, Jogo, Esporte e Luta -, em detrimento de outras temáticas que se tornam urgentes.

Já Sanches Neto (2003) critica a fundamentação do processo de ensino e aprendizagem na EF com base em teorias biológicas e psicológicas, que poderiam mascarar outras demandas relevantes, como a situação econômica, social e política dos alunos. Para o 
autor, o referencial dessa argumentação reside na fenomenologia existencial, que tem relacionado a experiência humana à capacidade orgânica que nosso corpo tem para responder às demandas do ambiente. Aliás, seria este o papel principal do corpo no comportamento inteligente. Segundo Sanches Neto e Lorenzetto (2011), tal possibilidade refere-se a uma integração do ser humano com o meio, e o corpo representaria uma continuidade entre a individualidade e o amplo contexto ambiental, que é físico, social, cultural, político, econômico etc. É praticamente a afirmação de uma continuidade entre o ser humano e o mundo, a noção de ser o corpo e não de tê-lo meramente; é, de certa forma, o ser-no-mundo, tal qual propõe a fenomenologia de Merleau-Ponty (2006).

A continuidade entre o ser humano e o mundo, conferida pelo corpo e pelo movimento intencional é explicada por Kunz (1991), que cita Tamboer para chamá-la de relação dialógica: compreendemos "esta relação homem-mundo via movimento como um contato dialógico". O movimento intencional, e compreendido pelo sujeito que se movimenta, é definido como o "Se-Movimentar". O sentido e o significado do movimento humano são influenciados pelo contexto (que se manifesta nas demandas ambientais) em que o sujeito está inserido. Segundo o autor, é, ao mesmo tempo, "um contato e um confronto com o mundo material e social", onde o ser humano é o sujeito do seu próprio agir.

[...] uma das formas de entendimento e compreensão do homem em relação ao seu contexto de relações, seu mundo... é assim uma ação em que o sujeito pelo seu Se-Movimentar, se introduz no mundo de forma dinâmica e através desta ação percebe e realiza os sentidos/significados em e para o seu meio (KUNZ, 1991, p.163).

Para que as intenções sejam evidenciadas e compreendidas nas aulas, é necessário que o professor problematize as demandas ambientais explicitamente com seus alunos, já que a influência do contexto nas relações humanas não pode ser refutada e as consequências do "Se-Movimentar" são imprescindíveis nesse diálogo 
com o ambiente. Ademais, se essa influência for compreendida e confrontada, as condutas dos alunos poderão ser fundamentadas em uma visão crítica e autônoma de suas realidades.

Desse modo, o objetivo específico desta investigação é problematizar o ensino de temas referentes à dinâmica do ambiente, compreendendo-os a partir do trabalho concreto de professores de $\mathrm{EF}$, que os identificaram como "demandas ambientais".

\section{A dinÂMICA do ambiente na Educação FísıcA}

Se todas as dinâmicas existem de modo integrado nas realidades - cultura, movimento, corpo e ambiente -, deveriam ser tratadas também de modo integrado nas aulas de EF. Segundo Sanches Neto (2003), seria necessária a explicitação das demandas ambientais e sua problematização, pois é o reconhecimento da relevância de certas demandas em detrimento de outras que pode principiar uma análise crítica dos alunos acerca da relatividade e do dinamismo do meio em que vivem. Compreender tais demandas intermitentes por meio de estratégias que requeiram vivências e reflexões dos alunos poderia promover uma postura investigativa, na qual há necessidade de organização dos processos de indução e dedução.

Conforme Peirce (1975), tanto o raciocínio indutivo como o dedutivo seriam limitados por um processo adaptativo no pensamento, uma vez que as características analisadas estão postas no ambiente que está sendo investigado. Haveria, segundo Peirce (1975), outra forma de raciocínio que é a abdução, correspondente a um tipo de pensamento radicalmente questionador e com um potencial transformador, já que admite a existência de soluções diferentes daquelas postas previamente no ambiente.

As demandas ambientais a serem problematizadas, portanto, seriam tão diversas quanto é o ambiente, mas foram agrupadas em seis categorias, para viabilizar a flexibilidade de sua sistematização no planejamento das aulas. Segundo Sanches Neto e Betti (2008), há demandas ambientais: físicas e naturais, históricas e geográficas, 
sociológicas e políticas, administrativas e econômicas, virtuais, estéticas e filosóficas. Ao sistematizar-se um período letivo, seria necessário primeiramente identificá-las, para que, em um segundo momento, os alunos as compreendessem de modo convergente entre si, e também de modo integrado aos temas dos demais blocos de conteúdos.

\section{Percurso Metodológico}

Para realizar esta investigação, os coautore ${ }^{1}$ encontraram-se sistematicamente, por quatro anos, para discutir suas práticas pedagógicas. Inicialmente, essa atividade foi proposta por nove professores que trabalhavam em escolas na região metropolitana de São Paulo, sem qualquer vinculação acadêmica institucional. Desde então, buscou-se coletivamente referenciais teóricos que subsidiassem reflexões aprofundadas sobre tais práticas.

Além da revisão bibliográfica acerca dos tópicos, foi utilizada a metodologia da pesquisa-ação (PHILLIPS; CARR, 2010) para subsidiar os encontros, expondo reflexões com critérios que permitiam maior coerência na retomada das práticas. A pesquisa-ação tem como pressuposto a identificação de um problema, elaboração e execução de plano de ação pelos sujeitos envolvidos, avaliação e retomada das ações a fim de identificar novos problemas.

Durante dois anos, foram organizados "laboratórios didáticos" para a vivência dos temas, que foram tratados anteriormente dentro de situações reais, em aulas na Educação Básica, com ênfase nos blocos de conteúdos associados às dinâmicas específicas da EF. Nesse período, ocorreram reflexões em conjunto sobre diversos elementos culturais: brincadeira, jogo, esporte, dança, ginástica, circo, luta, capoeira, vivências alternativas e atividades da vida diária. Já os demais blocos - referentes ao movimento, ao corpo (aspectos pessoais e interpessoais) e ao ambiente - foram integrados à dinâmica cultural, de modo concomitante.

${ }^{1}$ No âmbito do grupo autônomo de "professores-pesquisadores" de Educação Física. Disponível em: <http://br.groups.yahoo.com/group/professorespesquisadores>. Acesso em: 1 set. 2013. 
Assim, nesta investigação, o foco recaiu sobre os temas tidos como mais complexos durante a realização dos "laboratórios": no caso, aqueles associados às demandas do ambiente. Após a realização das vivências, os registros das discussões foram sistematizados mediante reflexões coletivas, pautadas em referenciais que permitissem avançar na teorização sobre os temas, tentando compreendê-los com mais distanciamento. Para isso, foram retomadas algumas "soluções" para problemas e situações específicas das aulas, compartilhando-se experiências no sentido de aprimorar as práticas com temas semelhantes.

\section{Problematização das demandas ambientais: PERSPectivas ADAPTATIVAS E TRANSFORMADORAS}

Ao problematizar o tratamento das demandas ambientais, foram identificadas perspectivas adaptativas e de transformação pelos professores, ao buscar contextualizar os conflitos implícitos ou explícitos $^{2}$ entre os valores pessoais dos alunos e aqueles aceitos e impostos. Há situações cotidianas em que as perspectivas adaptativas são necessárias, cabendo fomentar a criticidade dos alunos. Alguns princípios seriam pertinentes na adaptação, como a eficácia e a objetividade, buscando a economia energética do sistema locomotor - consideramos que há avanços nesta acepção, com base no trabalho de Manoel (2008) - e o racionamento na interação adaptativa, por meio de procedimentos que contemplassem a antecipação, vivência, reflexão e discussão ulterior.

Caberia também à intervenção do professor explicitar as influências ideológicas nas demandas ambientais, contextualizando as situações cotidianas em que as perspectivas transformadoras fossem necessárias. Nesse sentido, os princípios seriam os da

\footnotetext{
2Por exemplo: como lidar com argumentações conflituosas que expõem questões de gênero sobre as preferências de alunos e alunas? Poderíamos recorrer à vivência do tema que suscitou o conflito, depois à discussão sobre os problemas e interpretações dos alunos e alunas. A intenção seria elaborar argumentações cada vez mais complexas, com toda a turma, aproveitando excertos que permitissem tal empreendimento. Neste caso, seria pertinente 0 texto de Daolio (1995): "A construção cultural do corpo feminino ou o risco de transformar meninas em 'antas'".
} 
relevância e da subjetividade, evidenciados em condutas que também requeressem a alteridade, referentes ao enfrentamento do conflito entre os interesses pessoais e os alheios e coletivos.

Mediante a problematização, o propósito é que os alunos elaborem estratégias para se adaptarem às demandas complexas da realidade ou que possam encaminhar projetos para transformálas. Encontramos evidências de que os estudantes conseguem intervir efetivamente em sua própria realidade, com vistas à transformação das demandas ambientais, a partir dos conhecimentos que elaboram nas aulas de EF (VENÂNCIO; BETTI; SANCHES NETO, 2013).

Notamos que há tempos a perspectiva para problematizar a dinâmica do ambiente é tida como urgente nas aulas de EF, seja no sentido de adaptar (TANI et al., 1988) quanto no de transformar (SOARES et al., 1992) as condições que se apresentam na realidade. Contudo, os critérios para o encaminhamento das demandas ambientais em situações de aula são controversos.

O foco comum entre os professores participantes desta investigação é direcionado à transformação, porém há limites quando o espectro ideológico perpassa as realidades vividas no dia-a-dia, tanto pelos professores quanto por seus alunos. Por isso questionamos: até que ponto a perspectiva de adaptação também seria desejável em certas ocasiões de enfrentamento das realidades?

Ao abordar esse tipo de ensino "engajado" na sociedade contemporânea, percebemos que a relação com os conhecimentos sistematizados pela humanidade precisa considerar a relação com os saberes e as formas de elaborá-los pressupõe um vínculo com o mundo da vida. Precisa haver interação e confronto com este mundo para que o campo educativo tenha significado e faça sentido para os alunos.

Os modos de investigação historicamente socializados com base no modelo positivista ainda influenciam, de maneira significativa, a formação docente e, consequentemente, subjazem as diferentes concepções presentes no processo educativo. Tal modelo apoia-se na mensuração da observação, no fracionamento da realidade, 
controle das variáveis e previsão dos fenômenos estudados. Entretanto, as características dos fenômenos sociais, em geral, e dos fenômenos educativos, diferenciam-se dos fenômenos naturais observáveis e mensuráveis, pois, particularmente, apresentam-se como inacabadas, têm uma dimensão criativa, autoformadora, intencional, além de serem polissêmicas. Nossa intenção é fomentar a reflexão ao apresentar possibilidades para o encaminhamento das demandas ambientais nas aulas de EF, vinculadas ao sentido do "SeMovimentar" e à aproximação com o mundo pertinente às realidades concretas dos alunos. Isto pode permitir aos sujeitos perceberem-se influenciados e influenciando as diversas demandas que compõem o ambiente em que vivem, como maneira de reconhecer, pertencer e transformar sua relação com o mundo.

\section{Processo de Ensino e Aprendizagem Vinculado às Deman- dAs Ambientals}

O ambiente é demasiadamente complexo para que seja completamente compreendido por quaisquer meios interpretativos, incluindo modelos científicos. De todo modo, as ciências têm avançado em suas especialidades, permitindo apreender uma diversidade de conhecimentos já elaborados acerca das muitas demandas do ambiente. Nas aulas de EF, certas demandas nos parecem relevantes ao tratarmos da dinâmica do ambiente, constituindo-se como parte do conhecimento específico da EF, na medida em que são integradas às demais dinâmicas e seus temas. A Figura 1, a seguir, aponta essas inter-relações: 
Figura 1- Blocos de conteúdos temáticos

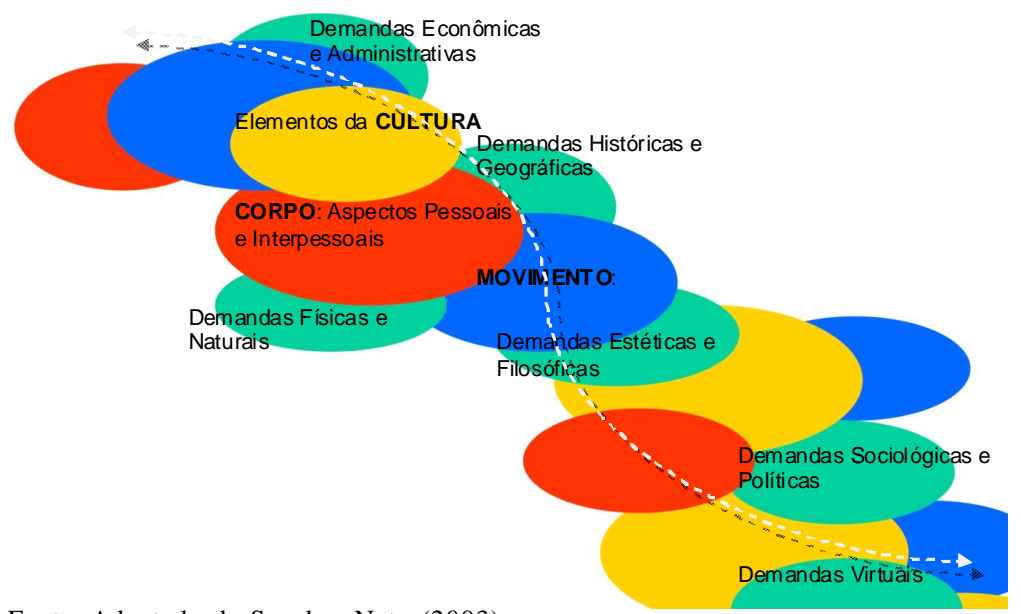

Fonte: Adaptado de Sanches Neto (2003).

A especificidade da EF significa que certas noções sobre as demandas do ambiente são conhecimentos pertinentes ao componente curricular. Caberia à EF tratar de demandas estéticas, no que se refere ao corpo, ou virtuais, quando diz respeito ao trato com o movimento ou políticas que influenciam os elementos da cultura. Isto é absolutamente diferente de constituir os professores de EF em filósofos, historiadores, geógrafos, economistas etc., porém, significa concordar que certos conhecimentos, arbitrariamente fragmentados pela metodologia científica em diversas áreas do saber, coadunam-se com a prática pedagógica dos professores de EF. Por esta razão, os professores precisam dominá-los, de modo a tornaremse competentes no aprofundamento de suas práticas.

Além disso, na escola, mesmo com todas as constrições estruturais ao trabalho docente, há professores que têm diferentes formações e podem compartilhar interpretações, tendo a possibilidade de organizar projetos comuns de intervenção. Conforme propõe Shulman (1986, 1987), esse domínio do conhecimento e o compartilhamento de experiências pedagógicas entre os professores somente é possível mediante a explicitação do conhecimento pedagógico dos conteúdos. 
As demandas ambientais dialogam entre si, compondo as realidades tangentes às aulas de $\mathrm{EF}$, interferindo na intencionalidade do sujeito do movimento (do corpo humano) e nos elementos da cultura. Por isso, é relevante manter uma aproximação com conhecimentos pedagógicos de conteúdos referentes a História e Geografia, Administração e Economia, Estética e Filosofia, Demandas Virtuais, Sociologia e Política, Física e Natureza (SANCHES NETO; BETTI, 2008).

Cabe, assim, questionar: qual é a relevância desses saberes e qual o sentido de ensinar e aprender cada demanda ambiental nas aulas de EF? Qual o conhecimento pedagógico necessário ao professor sobre esses temas para capacitá-lo a ensinar efetivamente aos alunos os conteúdos da dinâmica do ambiente? Nos tópicos a seguir, buscamos resumir o encaminhamento de algumas respostas, ainda que provisórias.

\subsection{DemandAS HISTÓRICAS E GEOGRÁFICAS}

Ao realizarmos coletivamente uma primeira sistematização de conteúdos, consideramos sua integração com os elementos da cultura. Elencamos o processo histórico dos elementos culturais logo no início de nossas preocupações, pensando na origem, tradição e também na crítica à ideia de "evolução" ou de hierarquia entre os diferentes fenômenos. Por exemplo: as relações temporais que caracterizam práticas diferenciadas entre o jogo e o esporte. Quanto às noções geográficas, ponderamos sobre a relatividade das características regionais: variações nos nomes ou regras, conforme o contexto, como na dança ou brincadeira.

Após essas primeiras aproximações, identificamos, o que de fato ensinávamos sobre tais demandas, vivenciando alguns temas selecionados por cada professor, de modo sistemático em nossos encontros, e buscamos aprofundar o referencial teórico sobre cada assunto, retomando os temas com mais criticidade. Notamos algumas 
questões no entendimento de como as sociedades estabelecem relações com os espaços físicos, ponto importante para compreensão da realidade no campo da EF.

As relações, simbologias e significados atribuídos aos lugares, constroem sua identidade, desenhando padrões de comportamento herdados e transmitidos a outras gerações. Esta visão tem auxiliado a análise crítica de professores e alunos e a contextualização das práticas corporais no desenvolvimento das aulas de EF (BRASIL, 2006).

Santos (2006, p.45) aponta a relevância da relação entre os espaços e as ações humanas "a partir do reconhecimento dos objetos na paisagem, e no espaço, somos alertados para as relações que existem entre os lugares. Essas relações são respostas ao processo produtivo no sentido largo, incluindo desde a produção de mercadorias à produção simbólica".

Essa visão geográfica admite vislumbrar a multiplicidade das práticas humanas. Assim, torna-se possível a compreensão das manifestações culturais que ocorrem de forma heterogênea, por conta de diversos fatores, como por exemplo: a percepção das nuances regionais de brincadeiras, esportes, danças etc.

Jesus (1999), em seu estudo sobre os aspectos geográficos das práticas corporais, enfatiza os esportes e "o estudo dos lugares e das relações entre a sociedade e sua base territorial". Para o autor, contextualizar as práticas corporais "envolve também as bases espaciais (localização, organização e dinâmica do território etc.) sob as quais determinada sociedade existe e se move". Jarek (2007) salienta a importância de valorizar ações e relações humanas indicativas do modo de vida de um povo, que seria a própria cultura. Essa visão potencializa o entendimento dos padrões, da permanência, das regularidades, das mudanças e transformações subjacentes aos elementos culturais. A compreensão crítica da construção dessas práticas e seu desenvolvimento permitem olhares diversificados e uma leitura de histórias silenciadas, que influenciam as práticas culturais atuais. 
A construção da consciência histórica ${ }^{3}$ possibilita aos professores reconhecer e validar os valores e práticas culturais, tanto na esfera individual quanto na coletiva, que não só constroem como também constrangem a identidade dos alunos. E aos alunos traz a consciência de que são sujeitos de uma complexa realidade social, que pode ser por eles ressignificada e transformada.

Trazer a perspectiva das relações temporais construídas por homens e mulheres, no passado e no presente (entendendo que as noções de "passado" e "presente" são construções culturais para lidar com a imanência do tempo cronológico), auxilia na problematização das temáticas e conteúdos tratados nas aulas de EF, permitindo a compreensão das práticas dos grupos sociais em tempos e espaços diferentes dos atuais. Dessa forma, abrem-se espaços para reflexões no sentido da construção plural de realidades próprias, colocando-nos como coautores da cultura, à medida que intencionamos investigar nossas práticas e as intersubjetividades que as constroem.

\subsection{Demandas administrativas E ECONÔMICAS}

Quanto às noções de administração, sugerimos alguns temas: organizar torneios esportivos, gincanas, festivais; elaborar e administrar regras e situações-problema; emancipar-se ante a influência do marketing das práticas corporais.

Em relação às noções de economia, ponderamos sobre questões mercadológicas, tais como: consumismo; critérios para atribuição de valores econômicos; supervalorização de determinadas modalidades esportivas em função de seu potencial econômico imediato; interferências da mídia no esporte; custo elevado do acesso aos espaços físicos e equipamentos de modalidades esportivas; merchandising e função do "garoto-propaganda" em produtos

\footnotetext{
${ }^{3}$ Schmidt e Garcia (2000, p.301) apontam que "a consciência histórica tem uma 'função prática' de dar identidade aos sujeitos e fornecer à realidade em que eles vivem uma dimensão temporal, uma orientação que pode guiar a ação, intencionalmente, por meio da mediação da memória histórica".
} 
esportivos; emancipação ante os interesses corporativos de patrocinadores (com maior ou menor exposição nas mídias).

No campo da EF, há indicativos para ensinar ambas as demandas, fomentando a criticidade dos alunos. Para isso, destacamos o trabalho original de Bracht (1986), onde o autor alerta que os alunos, ao praticarem meramente o esporte nas aulas, reproduzem o respeito às regras do jogo capitalista. Além disso, há trabalhos mais recentes que tratam da "escravidão econômica" no campo esportivo, como a denúncia de Rhoden (2006), ao analisar atletas profissionais bem pagos, que são usualmente os "modelos de condutas" para os alunos.

Nesse sentido, a análise da "escravidão econômica" contemporânea no campo da EF pode trazer à luz aspectos como a hierarquia entre os desejos e hábitos alimentados pelo consumismo e as necessidades concretas de existência e condições de vida e lazer, confrontando seus valores econômicos (SANCHES NETO; OYAMA, 1999). Há, ainda, um modelo mais ampliado das relações entre o capitalismo e a produção material no campo esportivo apresentado por Andrews (2011) $)^{4}$ O autor aponta que os sujeitos têm poucas opções ao interagir com o esporte corporativo no capitalismo contemporâneo, restringindo suas ações ao consumo de produtos, à circulação em espaços privados e à idolatria de celebridades. Nesse âmbito, o tratamento pedagógico das demandas a partir das aulas de EF, visando à emancipação dos sujeitos, poderia ampliar os graus de liberdade em suas ações.

\subsection{DeMANDAS ESTÉTICAS E FILOSÓFICAS}

Consideramos que o foco na estética perpassa a reflexão sobre os padrões de beleza enfatizados pelas mídias, o que pode constranger o sujeito. Tais padrões relacionam-se com a saúde e com características estéticas que os indivíduos adquirem, de acordo com as atividades cotidianas que praticam, bem como com seus hábitos posturais.

\footnotetext{
${ }^{4}$ ANDREWS, David L. Rolling with it? The perils of neoliberal Kinesiology. Palestra proferida no Seminário Ephysis, São Paulo, EEFE-USP, 31 ago. 2011 (palestra).
} 
Outras questões, como as dicotomias que valorizam a "mente" e minimizam a importância do corpo no comportamento inteligente, têm referências relevantes que as refutam no campo da EF (MEDINA, 1990). Como a maioria dos professores participantes desta investigação trabalha em escolas públicas, notamos que há também, no currículo de EF da rede estadual de São Paulo, temas alusivos ao "corpo, saúde e beleza", dentre outros passíveis de apreciação filosófica, como discutido nos trabalhos de Betti et al. (2010) e Freire (2012).

Para Betti et al. (2010), a apreciação estética está atrelada à busca por autonomia crítica e autocrítica, mediante competências e habilidades explicitadas no currículo paulista, no sentido de identificar e reconhecer, relacionar e analisar, elaborar, apreciar e intervir. Essa perspectiva é fundamentada na concepção crítico-emancipatória de Kunz (1991).

\subsection{Demandas VIRTUAIS}

Analisamos as possibilidades de tratar jogos eletrônicos utilizando, por exemplo, computadores conectados à internet (video games, consoles, simuladores), jogos de tabuleiro (xadrez) e representação (RPG - role playing games), lousa eletrônica ou equipamentos interativos ("tapete musical"). Tratar das demandas virtuais remete às redes e tecnologias de informação e comunicação (TIC) presentes nas sociedades contemporâneas, que se expandem pela interação humana, em uma relação dialógica do "atual" com o "virtual".

Há cada vez mais possibilidades de virtualização do corpo e simulação da realidade. O termo "virtual" é geralmente utilizado para designar algo que não existe, mas "o virtual não se opõe ao real, mas sim ao atual. Nesse sentido, [...] a virtualização não é uma desrealização, mas [...] um dos principais vetores de criação de realidade" (LÉVY, 1996).

$\mathrm{O}$ virtual (representações) simula o atual (práticas) sugerindo que, por analogia, ao atualizar o virtual possibilitamos a invenção de 
outra realidade. Lévy (1996) nos diz que a atualização é um processo de criação da realidade, solução de problemas, transformação de ideias. Para o autor "a virtualização pode ser definida como o movimento inverso da atualização", ou seja, "a passagem do atual ao virtual".

Por sua vez, as mídias - televisão, rádio, jornal, internet etc.possibilitam ao corpo tangível estar em vários "lugares" a um "só tempo" (BETTI, 2003). Temos TV e computador para a visão, telefone e rádio para audição, assim como sistemas de telemanipulação para o tato. Esses dispositivos virtualizam os órgãos do sentido (LÉVY, 1996) e viabilizam ao sujeito perceber e sentir o mundo a partir de outra realidade.

Feres Neto (2003) explica que a virtualização do esporte pode se estender a outros elementos culturais como jogo, luta, dança etc., uma vez que são criadas novas demandas para a sensibilidade e inteligibilidade do sujeito. Nesse processo, há outras formas de tratamento pedagógico das demandas virtuais, como jogos de botão ou histórias em quadrinhos.

\subsection{DeMANDAS SOCIOLÓGICAS E POLÍTICAS}

Tratamos aqui das implicações de algumas temáticas no campo da EF, como questões de gênero, etnia, discriminação, preconceito e práticas de lazer em condições de adversidade, miserabilidade ou privação de liberdade (CONCEIÇÃO, 2012; CORSINO, 2012).

Quanto às demandas sociológicas encaminhadas a partir das aulas, consideramos a inserção mais qualificada dos alunos em suas práticas de lazer, bem como o estímulo ao senso crítico em relação à privatização dessas práticas. Sobre as demandas políticas, ponderamos sobre o processo de empoderamento dos sujeitos, no sentido de emancipar os alunos no reconhecimento da liberdade relativa aos processos de escolha, tomada de decisão e pressupostos democráticos associados à valorização das preferências pelas práticas corporais. 
A necessidade de compreender o agir humano e sua intencionalidade permeia os processos de escolhas, de autonomia, de tomada de consciência pelos sujeitos. A esse respeito, Santos (2006, p.52), apoiado em Giddens, aponta que:

A limitação à consciência implica uma forma particular de tomar ação. A outra vertente na limitação das escolhas vem das limitações à própria ação. Depois que estamos munidos de um determinado quinhão de consciência, sabemos que as formas de ação que nos estão realmente abertas são pouco numerosas.

Uma preocupação coletiva, ao tratar a dinâmica do ambiente, consiste em seu encaminhamento político no processo de tomada de decisões entre professor e alunos, seja quando as decisões se dão de modo autoritário, por meio de ordens do professor para os alunos, seja quando se estabelece uma discussão para a tomada de decisão. Ambos os casos trazem uma relação política, considerando-a como a conjugação das ações individuais e grupais, dirigidas para um fim comum (DALLARI, 1999). A vida dos seres humanos em sociedade, as formas humanas de organização e a tomada de decisões podem impelir os sujeitos a eximirem-se da responsabilidade decisória. Nesse momento, o sujeito estaria tomando a decisão de permitir que outros sujeitos decidam em seu lugar.

\subsection{Demandas Físicas e naturais}

Provocados pelas reflexões de Negrão (2008), partimos do entendimento de que o termo grego physis significa tanto "física" quanto "natureza". Portanto, vislumbramos a integração entre ambas as demandas ambientais que a vida contemporânea parece insistir em separar, como se os seres humanos fossem criaturas à parte do "mundo físico e natural" (THOMAS, 2010). Conforme Lévi-Strauss (1973), a escola é uma ocasião social para a ruptura dos entendimentos ingênuos e, nesse sentido, as aulas de EF podem ser ocasiões para aprofundar as demandas físicas e naturais no entendimento dos alunos. 
Consideramos os elementos da fauna e da flora - i.e., os existentes nas vivências em ambientes que não se restringem à quadra da escola - para ampliação das possibilidades do "SeMovimentar". Nessa perspectiva, discutimos que a modalidade esportiva Basquetebol foi adaptada a partir de uma demanda climática adversa. Tratamos também do planejamento de aulas que utilizaram espaços externos à escola, como campos de Futebol em áreas urbanas, praças e praias. Na prática de atividades físicas em ambiente externo, há exposição direta a diversos fatores, como calor, frio, umidade do ar etc., que influenciam o desempenho. Além disso, há aspectos físicos, como ação e reação, inércia, gravidade etc., presentes nas práticas corporais de contato ou com manipulação de objetos.

Para ações autônomas, é necessário conhecer esses fatores, possibilitando reflexões que podem emancipar os sujeitos para práticas adaptativas ou transformadoras. Um exemplo de adaptação seria a discussão da restrição de atividades físicas diante da má qualidade do ar ou dos efeitos mais intensos do sol. Já uma possibilidade de transformação seria a discussão e estabelecimento de ações, por parte da sociedade, diante deste fato; por exemplo: no contexto da própria escola é prioritário que a quadra seja coberta, já que é um "ambiente de aula" tão relevante ao ensino como qualquer outra "sala de aula".

\section{Considerações finaIS: deSAFIOS PARA O TRATAMENTO PEDAGó- GICO DAS DEMANDAS AMBIENTAIS NA EF}

Ao refletirmos sobre a temática das demandas do ambiente, questionamos as influências que sofremos antes e a partir de nossa formação, que repercutem em nossas condutas como professores. Esta reflexão levou ao debate sobre a construção da identidade profissional e pessoal ao longo da vida.

A constituição da profissionalidade - ou identidade profissional - está também na relação do professor com a escola e os alunos. Segundo Libâneo (2000), é uma conquista do profissionalismo, termo 
que utiliza para se referir ao professor e sua postura em relação à escola, colegas de trabalho, à sua participação nas questões escolares, reuniões pedagógicas, eventos e conversas informais na sala dos professores, além da relação com os alunos. A identidade dos professores implica: dedicação ao trabalho, participação na construção coletiva do projeto pedagógico curricular, respeito à cultura de origem dos alunos, assiduidade, rigor no preparo e condução das aulas, compromisso com um projeto político democrático.

$\mathrm{O}$ tratamento das demandas ambientais por professores de $\mathrm{EF}$ representa um desafio nesse sentido apontado por Libâneo, consistindo em uma forma de contextualizar e flexibilizar o ensino às vinculações socioculturais dos alunos. Concordamos com o autor, quando este afirma que há uma questão epistemológica: a docência é um campo específico de saberes que se articulam na prática social.

Concluímos que saberes de várias áreas convergem para ensinar temas relacionados à existência humana. A EF trabalha necessariamente com conteúdos existenciais, pois se remete diretamente à vida dos alunos na dinâmica concreta e complexa do ambiente em que vivem. Assim, entendemos que os desafios imediatos para os professores abrangem três aspectos: a formação permanente para lidar com demandas pouco aprofundadas na formação inicial e contínua; a participação política ao expor suas convicções pessoais; e o empoderamento de si próprios e dos alunos, ao fomentar sua emancipação. 


\begin{abstract}
Environmental issues in school physical education: perspectives towards adaptation and transformation

Abstract: This investigation addresses the possibility of teaching themes related to environmental issues in Physical Education. We identified and classified such issues as: administrative and economic, aesthetic and philosophical, virtual, historical and geographical, sociological and political, physical and natural. Then, we discussed how the specific dynamics of culture, movement, and environment raises certain questions about each theme's relevance and its repercussions on teachers' professionalism. We believe that in the context of the daily intervention there are perspectives for both adaptation and transformation that might be further developed during classes in collaboration with the students.

Keywords: Curriculum. Physical Education. Socioeconomic factors. Cultural Characteristics.
\end{abstract}

Exigencias ambientales de la educación física en escuelas: perspectivas hacia la adaptación y la transformación

Resumen: Abordamos la posibilidad de enseñar temas que se relacionan con las demandas ambientales en la práctica pedagógica de la Educación Física. Se identifican y clasifican como: administrativa y económica, estética y filosófica, virtual, histórica y geográfica, sociológica y política, física y natural. Se discute cómo las dinámicas específicas cultural, del movimiento y ambiente levantan preguntas acerca de la relevancia del tema y sus repercusiones en la profesionalidad de los docentes. Creemos que en el contexto cotidiano hay perspectivas de intervención hacia la adaptación y transformación que pueden seguir desarrollándose en conjunto con los estudiantes durante las clases.

Palabras-clave: Curriculum. Educación Física. Factores Socioeconómicos. Características Culturales. 


\section{REFERÊNCIAS}

BETTI, Mauro et al. A proposta curricular de educação física do estado de São Paulo: fundamentos e desafios. In: CARREIRA FILHO, D.; CORREIA, W. R. (Orgs.). Educação física escolar: docência e cotidiano. Curitiba: CRV, 2010, p.109-128.

BETTI, Mauro et al. Por uma didática da possibilidade: implicações da fenomenologia de Merleau-Ponty para a EF. Revista Brasileira de Ciências do Esporte, Porto Alegre, v.28, n.2, p.39-53, jan. 2007.

BETTI, Mauro. Imagem e ação: a televisão e a EF escolar. In: BETTI, M. (Org.). Educação Física e mídia: novos olhares, novas práticas. São Paulo: Hucitec, 2003. p. 91-137.

BRACHT, Valter. A criança que pratica esporte respeita as regras do jogo... capitalista. Revista Brasileira de Ciências do Esporte, Porto Alegre, v.7, n.2, p.62-68, jan. 1986.

BRASIL, Ministério da Educação. Orientações curriculares para o ensino médio: ciências humanas e suas tecnologias. Brasília: MEC/SEB, 2006.

CONCEIÇÃO, Willian L. Lazer e adolescentes em privação de liberdade: um diálogo possível. 2012. 145f. Dissertação (Mestrado em Educação) - Programa de Pós-Graduação em Educação. Universidade Federal de São Carlos, São CarlosSP, 2012.

CORSINO, Luciano N.; AUAD, Daniela. O professor diante das relações de gênero na Educação Física escolar. São Paulo: Cortez, 2012.

DALLARI, Dalmo de A. O que é participação política. São Paulo: Brasiliense, 1999.

DAOLIO, Jocimar. A construção do corpo feminino ou o risco de se transformar meninas em "antas". In: ROMERO, E. (Org.). Corpo, mulher e sociedade. Campinas-SP: Papirus, 1995. p.99-108.

FERES NETO, Alfredo. A virtualização do esporte e suas novas vivências eletrônicas. In: BETTI, M. (Org.). Educação física e mídia: novos olhares, novas práticas. São Paulo: Hucitec, 2003.

FREIRE, Elisabete S. A construção de valores nas aulas de educação física: habitus e illusio no cotidiano de três professoras 2012. 186f. Tese (Doutorado em Educação Física) - Programa de Pós-Graduação em Educação Física, Universidade São Judas Tadeu, São Paulo, 2012.

JAREK, Gisele L. S. Cidades, culturas, memórias e identidades: uma proposta em educação patrimonial. Ágora, Santa Cruz do Sul, v.13, n.2, p.180-191, jul./dez. 2007. Disponível em: <http://online.unisc.br/seer/index.php/agora/article/viewFile/ 218/255>. Acesso em: 2 abr. 2013. 
JESUS, Gilmar de. A geografia e os esportes: uma pequena agenda e amplos horizontes. Conexões, Brasília, v.1, n.2, p.47-61, dez., 1999. Disponível em: <http:/ /polaris.bc.unicamp.br/seer/fef/viewarticle.php?id=411>. Acesso em: 2 abr. 2013.

KUNZ, Elenor. Transformação didático-pedagógica do esporte. ljuí-RS: Unijuí, 1991.

LARROSA BONDÍA, Jorge. Notas sobre a experiência e o saber de experiência. Revista Brasileira de Educação, Rio de Janeiro, n.19, p.20-28, jan./abr. 2002.

LÉVI-STRAUSS, Claude. Antropologia estrutural 2. 4. ed. Rio de Janeiro: Tempo Brasileiro, 1973.

LÉVY, Pierre. O que é virtual? São Paulo: Editora 34, 1996.

LIBÂNEO, José Carlos. Produção de saberes na escola: suspeitas e apostas. In: CANDAU, V. M. (Org.). Didática, currículo e saberes escolares. Rio de Janeiro: DP \& A, 2000. p. 11-45.

MANOEL, Edison de Jesus. A abordagem desenvolvimentista da educação física escolar - 20 anos: uma visão pessoal. Revista de Educação Física/UEM, Maringá, v.19, n.4, p.473-488, out./dez. 2008. Disponível em: <http://www.periodicos.uem.br/ ojs/index.php/RevEducFis>. Acesso em: 2 abr. 2013.

MATOS, Juliana Cassani et al. A produção acadêmica sobre conteúdos de ensino na educação física escolar. Movimento, v.19, n.2, p.123-148, abr./jun. 2013. Disponível em: <http://seer.ufrgs.br/Movimento/article/view/34213>. Acesso em: 19 mai. 2013.

MEDINA, João P. S. A educação física cuida do corpo e... mente: bases para a renovação e transformação da Educação Física. Campinas-SP: Papirus, 1990.

MERLEAU-PONTY, Maurice. Fenomenologia da percepção. 3. ed. São Paulo: Martins Fontes, 2006.

NEGRÃO, Ronaldo F. A origem temporal da expressão "educação física" e sua trajetória histórica: uma contribuição. São Paulo: Plêiade, 2008.

PEIRCE, Charles S. Semiótica e filosofia. São Paulo: Cultrix, EdUSP, 1975.

PHILLIPS, Donna K.; CARR, Kevin. Becoming a teacher through action research: process, context, and self-study. New York: Routledge, 2010.

RHODEN, William C. Forty million dollar slaves: the rise, fall, and redemption of the black athlete. New York: Three Rivers, 2006.

SANCHES NETO, Luiz. Educação física escolar: uma proposta para o componente curricular da $5^{\mathrm{a}}$ à $8^{\mathrm{a}}$ série do ensino fundamental. 2003. 189f. Dissertação (Mestrado em Pedagogia da Motricidade Humana) - Programa de Pós-Graduação em Ciências da Motricidade, Unesp, Rio Claro, SP, 2003. 
SANCHES NETO, Luiz; BETTI, Mauro. Convergência e integração: uma proposta para a educação física de $5^{\underline{a}}$ à $8^{\underline{a}}$ série do ensino fundamental. Revista Brasileira de Educação Física e Esporte, São Paulo, v.22, n.1, p.5-23, jan./mar. 2008. Disponível em: <http://www.revistas.usp.br/rbefe/article/view/16678/18391>. Acesso em: 2 abr. 2013.

SANCHES NETO, Luiz; LORENZETTO, Luiz Alberto. Conhecimento do corpo. In: DARIDO, S. C.; RANGEL, I. C. A. (Orgs.). Educação física na escola: implicações para a prática pedagógica. Rio de Janeiro: Guanabara Koogan, 2011. p.137-157.

SANCHES NETO, Luiz; OYAMA, Edison R. Da escravidão negra à "escravidão econômica" contemporânea: implicações para a educação física no Brasil. Discorpo, São Paulo, n.9, p.45-71, 1999.

SANTOS, Milton. A natureza do espaço geográfico: técnica e tempo, razão e emoção. 4. ed. São Paulo: EdUSP, 2006.

SCHMIDT, Maria Auxiliadora S., GARCIA, Tania Maria F. B. A formação da consciência histórica de alunos e professores e o cotidiano em aulas de história. Cadernos Cedes, Campinas, v.25, n.67, p. 297-308, set./dez. 2005. Disponível em: <http:// www.cedes.unicamp.br>. Acesso em: 2 abr. 2013.

SHULMAN, Lee S. Knowledge and teaching: foundations of the new reform. Harvard Educational Review, Cambridge, v.57, n.1, p.1-22, fev. 1987.

SHULMAN, Lee S. Those who understand: knowledge growth in teaching. Educational Researcher, Washington, v.15, n.2, p.4-14, fev. 1986.

TANI, Go et al. Educação física escolar: fundamentos de uma abordagem desenvolvimentista. São Paulo: EPU, EdUSP, 1988.

THOMAS, Keith. O homem e o mundo natural: mudanças de atitude em relação às plantas e aos animais (1500-1800). São Paulo: Companhia das Letras, 2010.

VENÂNCIO, Luciana, BETTI, Mauro, SANCHES NETO, Luiz. How one physical education teacher and former students position themselves before the relationship to knowledge? In: ISATT BIENNAL CONFERENCE ON TEACHERS AND TEACHING: EXCELLENCE OF TEACHERS? PRACTICE, POLICY, RESEARCH, 16, 2013. Book of abstracts... Ghent University, [Bélgica]. p.290-292, jul. 2013.

Endereço para correspondência

Luiz Sanches Neto

Rua Tuiuti, 606 - Apt.15, Bloco 3 (Flamboyant)

Tatuapé - São Paulo-SP - Brasil

CEP 03081-015

Recebido em: 10.07.2013

Aprovado em: 26.08.2013

ovimento, Porto Alegre, v. 19, n. 04, p. 309-330, out/dez de 2013. 